\title{
Self-inflicted gunshot injury to the external genitalia: a case report and review of literature
}

\author{
Anselm Okwudili Obi ${ }^{1,2^{*}}$, Augustine Obasi Ulebe ${ }^{1}$, Ugochukwu Uzodinmma Nnadozie ${ }^{1,2}$, \\ Charles Chidiebele Maduba' ${ }^{1}$ Chukwudi Ogonnaya Okorie ${ }^{1,2}$ and Obinna Nnabuife Anikwe ${ }^{3}$
}

\begin{abstract}
Background: Gunshot wounds of the external genitalia are rare. Rarer still are civilian self-inflicted gunshot wounds of the external genitalia. The protocol for the management of gunshot wounds of the penis especially with respect to urethral injuries is not fully established.

Case presentation: We present a 27-year-old male undergraduate student, who accidentally shot himself in the penis. He sustained American Association for the Surgery of Trauma (AAST) grades IV to V injuries to the penis, scrotum and left testes. He was managed in a multistage, multi-disciplinary fashion including staged buccal mucosal graft repair of $4 \mathrm{~cm}$ proximal penile urethral defect with satisfactory cosmetic and functional outcome.

Conclusions: Excellent functional and cosmetic results may be obtained after severe penetrating trauma to the external genitalia even in low resource centres in the hands of non-reconstructive urologists. Buccal mucosal graft is a viable option for two stage reconstruction of the urethra.
\end{abstract}

Keywords: Buccal mucosal graft, Case report, External genitalia, Gunshot wound, Self-inflicted injury, Urethroplasty

\section{Background}

Genitourinary injuries are relatively uncommon as they constitute between 2.5 and $18 \%$ of all trauma [1-3]. Most documented cases are from the theatres of war $[1,3,4]$, with fewer but increasing number of cases being reported in the civilian setting $[2,5-7]$. This has been attributed to increase in crime [5, 6].The penis is involved in 8\%-9.5\% of all genitourinary injuries [1-3]. The rarity of male external genital injuries has been attributed to its relative protection by the thighs and the mobility and size of the penis [8]. Another plausible reason is that the external genitalia is a small target, since it constitutes less than $1 \%$ of the body surface area [9].

The different components of the male external genitalia, the penis, scrotum and testes may be injured singly or in combination and to variable degrees with or without

\footnotetext{
*Correspondence: draoobi@yahoo.com

${ }^{1}$ Department of Surgery, Alex Ekwueme Federal University Teaching

Hospital, PMB 102, Abakaliki, Ebonyi State, Nigeria

Full list of author information is available at the end of the article
}

extra genital organ involvement. Fortunately, the external genitalia injuries are rarely life threatening [10] compared to the extra genital organ injuries of which the proximal lower extremity is the most frequently involved $[2,5,7]$.

Successful treatment of gunshot wounds of the external genitalia depends on early surgical intervention. Characterization of nature and extent of injury is important. In this regard ultrasonography and urethrography are useful tools $[5,8,10]$. So also is the American Association for the Surgery of Trauma (AAST) scoring system [10]. The AAST scoring system enables standardization of cases and outcomes research [10]. Lifelong disability from stricture, impotence, infertility and incontinence can result from less than optimal management of these injuries or be dictated by injury severity. The trauma surgeon should aim at restoring normal anatomy and function without compromising cosmesis.

The protocol for the management of gunshot injuries of the penis especially with respect to urethral injury is not well established. Most reports in the literature describe minor urethral lacerations that were repaired primarily 
$[6,10]$, or by urethral stenting catheter and suprapubic urinary diversion alone [11]. On the other hand, studies documenting major urethral disruptions do not detail the type or outcome of staged urethroplasty done $[8,10]$. We describe here the management of major urethral disruption by staged buccal mucosal graft urethroplasty. In the light of this, we believe that this case report will be a useful addition to the growing literature on the management of severe gunshot wounds of the external genitalia. It also shows that excellent outcome can be achieved in the hands of non-reconstructive urologists in resource poor settings. Moreover to the best of our knowledge, there is no report in the literature of accidental civilian, self-inflicted gunshot injury to the external genitalia.

\section{Case presentation}

Following institutional ethics review board approval and haven obtained written informed consent of the patient, we present a 27-year-old male undergraduate student of one of our tertiary institutions who presented with $12 \mathrm{~h}$ history of self-inflicted gunshot injuries to the external genitalia and right upper medial thigh. Patient was alleged to be a cultist and in illegal possession of firearms. He was said to have accidently shot himself in the external genitalia while trying to bring out his gun from his trouser pocket. He had no known pre-trauma comorbidities. He was initially treated at a peripheral hospital where initial resuscitation and suturing of the right thigh injury was done before referral to our facility for expert care. The patient had no contributory past medical or surgical history.

Examination revealed a patient with stable vital signs with injuries to the external genitalia and upper medial aspect of the right thigh (Fig. 1). The external genitalia showed degloving penile shaft injury extending from the base of the penis to coronal sulcus with devitalization and loss of about $4 \mathrm{~cm}$ segment of the proximal penile urethra and its corpus spongiosum (Fig. 2a, b). The extensive skin loss may be secondary to thermal injury considering the closeness of the shot.

The proximal and distal urethral segments were patent. $\mathrm{He}$ had in addition lacerations of the tunica albuginea of the corpora carvenosa. He also had extensive anterior scrotal wall avulsion with exposure of both testes (Fig. 1). The left testis was shattered but the right testis was viable. Other examination findings including digital rectal examination were unremarkable.

The $\mathrm{x}$-ray of the right thigh revealed soft tissue swelling with no bony involvement. Other investigations including urinalysis, complete blood count, retroviral screening, abdomino-pelvic ultrasound scan and chest $\mathrm{x}$-ray were normal. A clinical diagnosis of self-inflicted severe

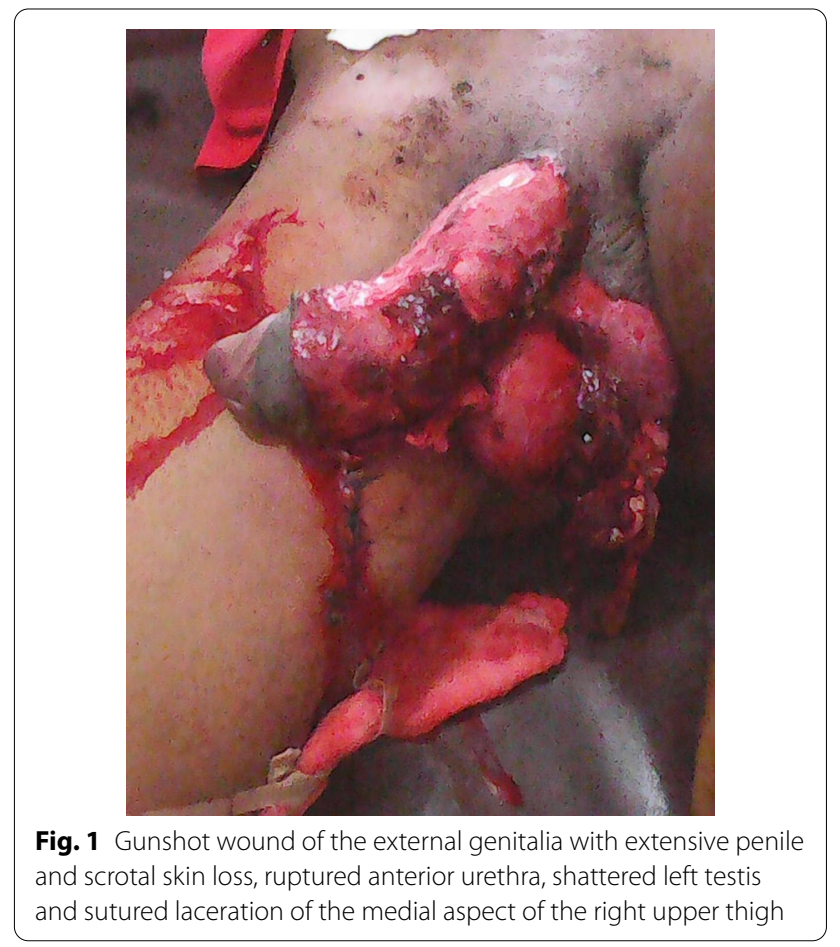

genital gunshot injury with shattered and devitalized left testis was made.

The patient was placed on intravenous broad spectrum antibiotics and analgesics. He was taken to theatre within $24 \mathrm{~h}$ of presentation. Urine was diverted by suprapubic cystostomy. This was followed by copious irrigation of the wound with normal saline, wound exploration and cautious debridement. He was assessed to have AAST Grade IV Penile injury, AAST Grade IV scrotal injury and AAST grade V left testicular injury. A left orchidectomy was done with primary repair of the scrotal lacerations. The lacerations of the tunica albuginea of the corpora carvenosa and spongiosum were repaired with $3 / 0$ vicryl sutures. A size 16F silicone urethral catheter was passed into the proximal urethra and left in place. Post-operatively the intravenous broad spectrum antibiotics and analgesics were continued in addition to haematinics, and daily penile wound dressing. Patient was discharged after eight weeks of treatment on his first admission but spent an extra eight weeks in hospital before he could settle his bills.

Patient was re-admitted at 6 months post injury and underwent first stage buccal mucosal graft (BMG) urethroplasty. Buccal mucosal graft was quilted onto the corpora carvenosa between the proximal and distal urethral openings with suturing of the BMG to the edges of the urethra to form a new urethral plate. He was discharged home on the 14th post-operative day. 


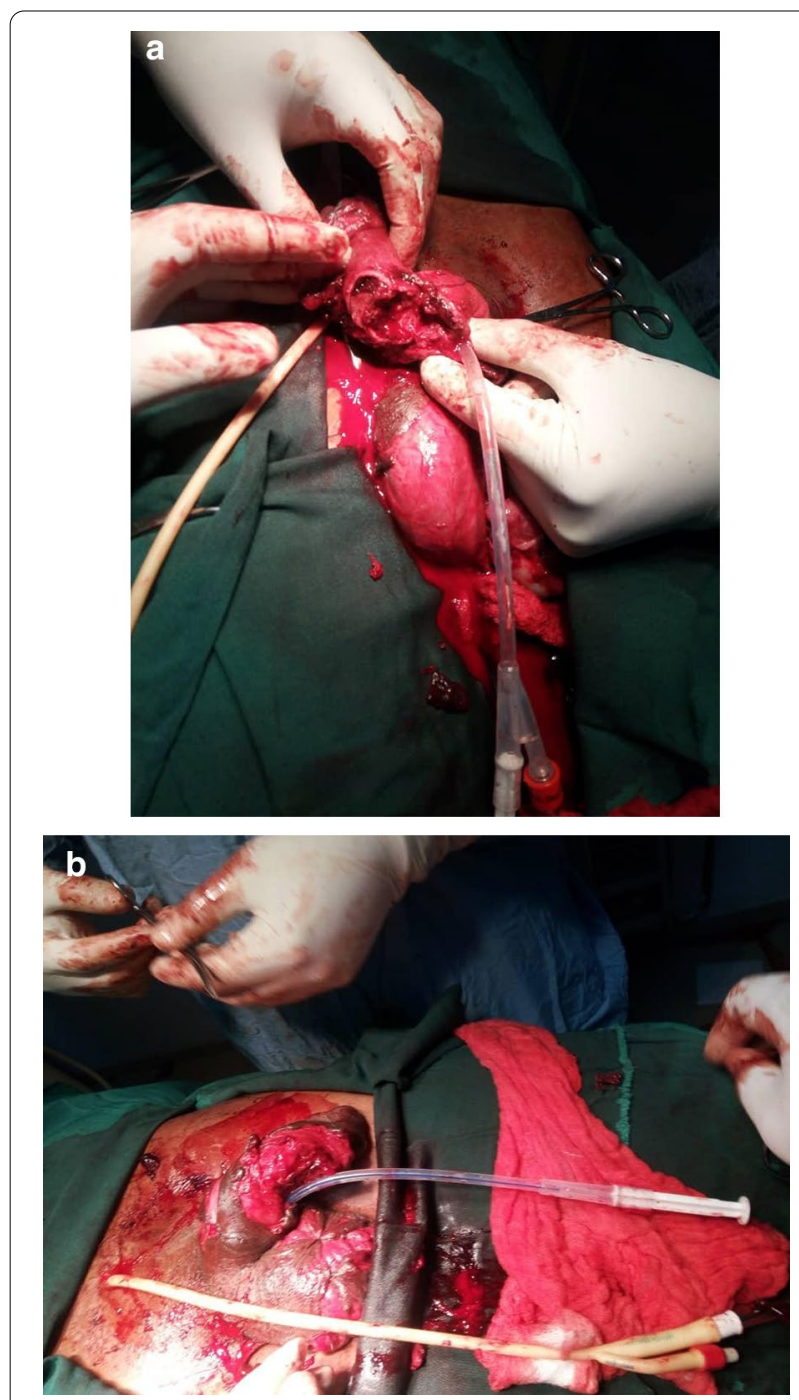

Fig. 2 a Gunshot wound of the external genitalia showing extensive urethral and corporal disruptions. $\mathbf{b}$ Gunshot wound of the external genitalia. Corporal disruptions have been repaired primarily. Also showing sutured scrotal lacerations after a left orchidectomy

Assessment of the penis at 10 months post injury showed good take of BMG to form a supple neo-urethral plate (Fig. 3). At 16 months post injury patient underwent 2 nd stage urethroplasty and penile skin cover. The BMG neo-urethral plate was tubularized using vicryl 3/0 suture in Thiersch-Duplay fashion over size $22 \mathrm{Fr}$ catheter to create a $22 \mathrm{Fr}$ urethra. A size $16 \mathrm{~F}$ silicone urethral catheter was left in place as a stent. Orthoplasty was also done in collaboration with the plastic surgery team. Penile scar tissue release and excision was done. At the same sitting the penis was covered with split-thickness skin graft (STSG) harvested from the patients right thigh. The urethral stenting catheter was removed on the

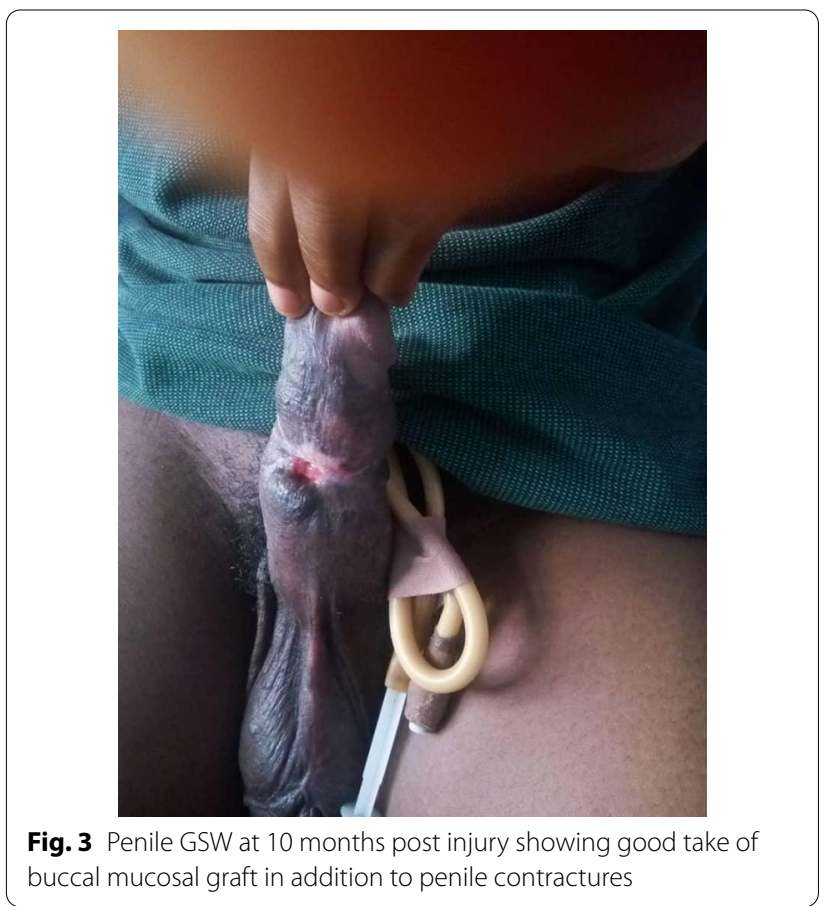

28th post-operative day. Adequate urine flow and Qmax of $25 \mathrm{ml} / \mathrm{s}$ was noted. A retrograde urethrogram was requested for the purpose of documenting the urethral repair. Patient could not afford the investigation. He was discharged home the next day and has been on 2 monthly follow-up at the out-patient clinic. He had a satisfactory cosmetic outcome (Fig. 4) and had subjective adequate erection. Objective assessment of erectile function using the international index of erectile function questionnaire was not done on this patient and this is a major limitation of this case report. Patient was last seen at 8 months post discharge.

\section{Discussion}

In the last two decades, there has been an increase in student cultism and gun violence in campuses of tertiary institutions in our country. This injury is a direct consequence of such violence. It is an interesting case of assailant turned victim. There is no report in the literature of civilian accidental self-inflicted gunshot injury to the male external genitalia but several cases of military $[1,3$, $4]$ and civilian $[2,7,12]$ gunshot injuries of the external genitalia have been documented. The age of our patient falls within the age range and is close to the mean ages of 29.0 years and 30.4 years, respectively, reported by previous authors for civilian gunshot wounds [2,7].

Injury severity in gunshot wounds is determined by kinetic energy (KE) transferred by the bullet which in turn is directly proportional to the mass and velocity of 


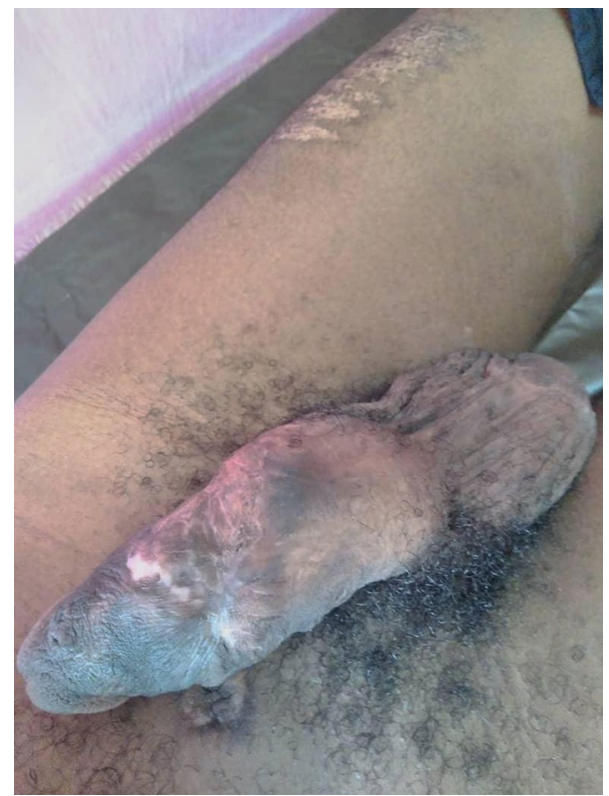

Fig. 4 Penile GSW showing satisfactory take of penile skin graft and absence of penile chordee

the bullet [13].We could not ascertain the type of gun used by our patient but he obviously sustained the maximum impact from the bullet since he accidentally shot himself from his trouser pocket. This is evidenced by the high AAST scores documented.

Successful treatment of gunshot wounds of the external genitalia depends on early surgical exploration, broad spectrum antibiotic cover, anti-tetanus prophylaxis, debridement of the wounded structures and primary repair of lesions that can be repaired primarily [1-5]. The preservation of potency, normal micturition, fertility and a cosmetically acceptable phallus are major treatment goals [2-7]. Debridement should be cautious because marginally viable tissues may eventually survive due to the rich blood supply of the perineum [5]. Majority of patients will need surgical exploration $[1-3,10]$ as in our index case with only a very small percentage being managed non-operatively $[5,10]$. Non-operative management of external genitalia injuries is controversial and should be reserved only for the most superficial of injuries $[5,10]$. Extra genital organ injuries may be present. They should be sought for, evaluated and treated on their own merit. The extra genital organ injuries are usually more life threatening than the external genitalia injuries and should therefore be given priority attention [4]. Our index patient had extra genital organ injury to the upper thigh that did not involve major vessels or bone.

The penis is injured in $8-9.5 \%$ of all genitourinary trauma [1, 2]. The evaluation of penile injuries may require ultrasonography to detect occult corporal injuries. Our index case did not have ultrasonography done. Injuries to the corpora carvenosa should be repaired with non-absorbable sutures as was done in this index case while avoiding exploration of the cavernous tissue as this may cause more damage and result in impotence [8]. The urethra may be affected in 11-29\% of penetrating penile injuries $[5,10,14]$. Urethral injuries can vary from mild contusions, urethral lacerations to major urethral disruptions $[6,8,10,11]$. Our index patient had a greater than $2 \mathrm{~cm}$ urethral defect (AAST grade IV penile injury). A retrograde urethrogram is recommended for evaluation of urethral integrity in all patients with penetrating GSW of the penis $[5,8,10]$. However, some authors have relied on the triad of absence of blood at the meatus, spontaneous voiding or easy catheterization and absence of haematuria as sufficient evidence of urethral integrity [8]. Our index patient did not have a urethrogram. He had a very obvious urethral injury and there was easy urethral catheterization. Management of minor urethral lacerations is controversial. Some authors have documented good results with urethral stenting catheter and suprapubic urinary diversion alone [11], while others recommend primary repair or end to end anastomosis $[4,6,10]$. For major urethral disruptions, there is a consensus of opinion that staged urethroplasty gives the best outcome $[4,8]$. However, there is scanty evidence on the types and outcome of staged urethroplasty done. Our index patient had an AAST grade V urethral injury that was managed by staged buccal mucosal graft urethroplasty with satisfactory outcome even though the authors are non-reconstructive urologists. Buccal mucosa is readily available, easy to harvest, hairless, accustomed to a wet environment and resilient to infection. It is also a thick epithelium with a thin lamina propria that allows for early inosculation [15].

The scrotum and testes are commonly injured along with the penis. Phonsombat et al. [5] documented 39\% testicular involvement in 54 patients with gunshot injury to the external genitalia. Penetrating scrotal wounds often require exploration to assess the extent of testicular damage as was done in our index case. In doubtful cases a scrotal ultrasound may be done to determine the viability of the underlying testis [10]. Attempt should be made to preserve the testes but shattered and obviously nonviable testis should be removed [10].Our index patient had a shattered and devitalized left testis that obviously had to be removed. Orchidectomy rates vary from study to study and may be as high as $61 \%$ [10].

Substantial penile skin loss may occur with severe gunshot injuries to the external genitalia as documented in our case. Our patient had almost $80 \%$ penile skin loss (Fig. 1) that was successfully covered with thick split 
thickness skin graft (Fig. 4). The need for proper coverage of the penile shaft with sensate, stable, supple and aesthetically acceptable skin cannot be over-emphasized. The split thickness skin graft is a desirable option as it requires less than ideal condition for survival conferring a major advantage over the full thickness skin graft [16] however it shows more secondary contracture [17]. Fortunately, our index patient recovered fully without contractures.

The upper thigh is the most commonly injured extra genital organ associated with gunshot injury to the external genitalia $[2,5,8]$. The degree of involvement may range from soft tissue injury alone to bony or major vessel involvement [2, 8]. Our index patient had only soft tissue injury to the upper thigh that was sutured at the referral hospital. It healed primarily and did not need further attention.

\section{Conclusion}

Excellent functional and cosmetic results may be obtained after severe penetrating trauma to the external genitalia even in the hands of non-reconstructive urologists working in a low resource centre. Buccal mucosal graft is a viable option for two stage reconstruction of the severely damaged anterior urethra.

\section{Abbreviations \\ AAST: American Association for the Surgery of Trauma; BMG: Buccal mucosal graft; KE: Kinetic energy.}

\section{Acknowledgements}

We have no acknowledgements.

\section{Authors' contributions}

$\mathrm{AO}$ - Conception, data acquisition, literature search and review of literature, manuscript writing. editing of manuscript, approval of the submitted version, agreed both to be personally accountable for his own contributions and certifies the accuracy or integrity of other parts of the work. AU-Data acquisition, literature search, manuscript writing. Editing of manuscript, approval of the submitted version, agreed both to be personally accountable for his own contributions and certifies the accuracy or integrity of other parts of the work. UN-Data acquisition, literature search and review of literature, manuscript writing. Editing of manuscript, approval of the submitted version, agreed both to be personally accountable for his own contributions and certifies the accuracy or integrity of other parts of the work. CM-Data acquisition, literature search and review of literature, manuscript writing. Editing of manuscript, approval of the submitted version, agreed both to be personally accountable for his own contributions and certifies the accuracy or integrity of other parts of the work. CO_Literature search and review of literature, editing of manuscript, approval of the submitted version, agreed both to be personally accountable for his own contributions and certifies the accuracy or integrity of other parts of the work. OA-Data acquisition, literature search, editing of manuscript, approval of the submitted version, certifies the accuracy or integrity of other parts of the work. All the above listed authors have read and approved the manuscript.

Funding

We have not received any funding for this publication.
Ethics approval and consent to participate

The publication was approved by the Ebonyi State University Ethics board.

Consent to participate

Not Applicable.

Competing interests

We have no competing interests to declare.

\section{Consent for publication}

Written informed consent for publication was obtained from the subject.

\section{Author details}

${ }^{1}$ Department of Surgery, Alex Ekwueme Federal University Teaching Hospital, PMB 102, Abakaliki, Ebonyi State, Nigeria. ${ }^{2}$ Department of Surgery, Ebonyi State University Teaching Hospital, Abakaliki, Ebonyi State, Nigeria. ${ }^{3}$ Department of Surgery, University of Nigeria Teaching Hospital, Enugu, Nigeria.

Received: 1 April 2020 Accepted: 5 January 2021

Published online: 21 January 2021

\section{References}

1. Hudolin T, Hudolin I (2003) Surgical management of urogenital injuries at a war hospital in Bosnia-Herzegovina, 1992 to 1995. J Urol 169:1357-1359

2. Najibi S, Tannast M, Latini JM (2010) Civilian gunshot wounds to the genitourinary tract: Incidence, anatomic distribution, associated injuries, and outcomes. Urology 76(4):977-981

3. Al-Azzawi IS, Koraitim MM (2014) Urethral and penile war injuries: the experience from civil violence in Iraq. Arab J Urol 12(2):149-154

4. Salvatierha O Jr, Rigdon WO, Norris DM, Brady TW (1969) Vietnam Experience with 252 urological war injuries. J Urol. 101:615-620

5. Phonsombat S, Master VA, McAninch JW (2008) Penetrating external genital trauma: a 30-year single institution experience. J Urol 180:192-196

6. Husmann DA, Boone TB, Wilson WT (1993) Management of low velocity gunshot wounds to the anterior urethra: the role of primary repair versus urinary diversion alone. J Urol 150:70-72

7. Cerwinka WH, Block NL (2009) Civilian gunshot injuries of the penis: the Miami experience. Urology 73:877-880

8. Gomez RG, Castanheira ACC, McAninch JW (1993) Gunshot wounds to the male external genitalia. J Urol 150:1147-1149

9. Sinnatamby CS (2006) Chapter 1: last's anatomy; regional and applied, 11 th edn. Elsevier, Edinburgh, $\mathrm{p} 2$

10. Mohr AM, Pham AM, Lavery RF, Sifri Z, Bargman V, Livinston DH (2003) Management of trauma to the male external genitalia: the usefulness of American Association for the surgery of trauma organ injury scales. J Urol 170:2311-2315

11. Pontes JE, Pierce JM Jr (1978) Anterior urethral injuries: four years of experience at the Detroit general hospital. J Urol 120:563-564

12. Dogo HM, Ibrahim AG, Gana YL (2016) Missile injuries to the external genitalia: a five year experience in Maiduguri, North Eastern Nigeria. Int J Res Med Sci 4(7):2964-2966

13. Rozen N, Dudkiewicz I (2011) Wound ballistics and tissue damage. In: Lerner A, Soudry M (eds) Armed conflict injuries to the extremities, a treatment manual, vol XVI. Springer, Berlin, pp 21-33. https://doi. org/10.1007/978-3-642-16155-1_2

14. Cline KJ, Mata JA, Venable DD, Eastham JA (1998) Penetrating trauma to the male external genitalia. J Trauma 44:492-494

15. Bhargava S, Chapple CR (2004) Buccal mucosal urethroplasty: is it the new gold standard? BJU Int 93:1191-1193

16. Thakar HJ, Dugi DD (2013) Skin grafting of the penis. Urol Clin North Am 40(03):439-448

17. Scherer-Pietramaggior SS, Pietramaggiori G, Orgil DP (2013) Skin graft. In: Neligan PC (ed) Plastic surgery, vol 1, 3rd edn. Elsevier, New York, p 320

\section{Availability of data and material}

Not applicable. 